

\section{Innovation Driven Emerging Technology from two Contrary Perspectives: A Case Study of Internet}

\author{
Dr. Mehmet Lutfi ARSLAN \\ Dr. Sadi Evren SEKER \\ Dr. Cevdet KIZIL
}

\section{Introduction}

In 1945, Dr. Vannevar Bush, Director of the Office of Scientific Research and Development, wrote an article about the application of science to warfare. As a coordinator of the activities of leading American scientists, he called for a new relationship between science and scientist. To him, "for many years inventions have extended man's physical powers rather than the powers of his mind." Now, "instruments are at hand which, if properly developed, will give man access to and command over the inherited knowledge of the ages. The perfection of these pacific instruments should be the first objective of our scientists as they emerge from their war work."

Some 40 years later, Langdon Winner proposed a similar perspective to technology. While establishing technological systems, he urged us to reflect upon the potential consequences of such systems. If we cannot interfere at the beginning of designing and developing a right system which means a right world we live in, then, we would not be able to deal with the outcomes. "because choices tend to become strongly fixed in material equipment, economic investment, and social habit, the original flexibility vanishes for all practical purposes once the initial commitments are made.",2

Bush's view of science is optimistic, because he has a very naïve faith in the power of science and scientists. According to this view, science acts in circumstances of scientists' own making and choosing. What we have is our work and development. By the same token, what we prospect is our plans and

${ }^{1}$ Vannevar Bush, “As We May Think”, Atlantic Monthly, 1945,

http://www.csi.uottawa.ca/ dduchier/misc/vbush/awm t.html.

${ }^{2}$ Langdon Winner, The Whale and the Reactor A

Search for Limits in an Age of High Technology, The

University of Chicago Press, 1986, Chapter 1. designs. It is a formation of ordinary science work and thus outcomes are determined. This sort of science view implies not only a positivist and enlightened world paradigm but also a hidden agenda of imposing power from an ivory tower in which scientists live.

Winner has a sort of pessimistic perspective towards the role of technology in the society. If it is possible to determine the outcomes, then there is no possibility to have uncertainty, which is the must of a democratic regime. Winner attempts to avoid undesirable outcomes of technological advances, yet at the expense of freedoms.

Both Winner and Bush are acceptable, in terms of having positive perceptions of science or avoiding negative effects of technology. However, it seems that efforts to control the negative effects of technology or to have positive effects of it to extend the power of mind, as is Bush's attempt, are to threaten or to restrict freedoms of society. Yet, the very nature of science and particularly technological advancements stems from the freedom of individual decision-making. This is a value that fosters the development of societies and individuals.

If, people want technological developments and positive contributions of science to their lives, even if they also want to have their freedoms and individually take their own decisions with their consequences either positive or negative, the question that whether it is possible to have both simultaneously raises another issue: What are the roles of decision makers in shaping the technology?

An intense debate over the role of technology in society in late 1960 s between Emmanuel Mesthene and John McDermott inspired me to deal such an issue. Mesthene, director of Harvard Program on Technology and Society at that time, argued that technology, neither an alloyed blessing for man nor an unmitigated curse, is a selfcorrecting system. On the other hand, to McDermott, technology had its own politics. Focusing on the nature of contemporary application of technology like in Vietnam War, he defined technology as "systems of rationalized control over larger groups of men, events, and machines by small groups of technically skilled men operating through organized hierarchy." "3 Though the debate was based upon the different perspectives of rightist and leftist politics, their opposite definitions of decision makers in shaping the technology highlight a fundamental point to my argument: The positions and roles of decision makers in creation of technology.

\footnotetext{
${ }^{3}$ John McDermott, "Technology: The Opiate of the Intellectuals", in Albert H. Teich (Editor), Technology and Future, St. Martin's Press, Fifth Edition, NY, 1990, p. 110.
} 
Our chief interest lies in the question of whether they could be a determinant factor. In order to deal such an ambiguous issue, we are specifically interested in exploring this concern in a new technological form, Internet, whose construct is shaped by a high level of commitment of its pioneers. So, in final analysis, figuring out what is the role of decision makers of technology in shaping the nature of that technology, we argue that if internet, as a newest technological form is so far maintaining both freedom of individual decision making and virtues and advantages of technology, it is possible because of the fact that from the very beginning its pioneers, designers, and architects are eagerly committed to do so. We will investigate the theoretical basis of this idea, and discuss the early history of the Internet in terms of the commitment of its pioneers, decisionmakers and potential decision-makers that affect the development of the Internet. As long as decentralized, interoperable, and open nature of internet technology survives, we assert that this would be possible if only there are committed designers, architects and organizations that can elevate themselves in such a position that they exhibit no drive for commercial or political power. $^{4}$

Paper proceeds in the following ways: First, comparing and contrasting two opposite views of decision makers of technology, we derive some specific guidelines that are helpful in determining the characteristics of decision-makers of technological advancements. Then, particularly in the example of internet, we try to reveal the commitment of pioneers of the Internet to open, free and decentralize structure of that new technological form, which otherwise would not be possible. We examine their positions, as well as present efforts in terms of individual decision making and politics of technology.

\footnotetext{
${ }^{4}$ Having said that, I have to admit that my view on internet as free and open architecture could be seen a bit naïve by some. For instance, one who sees global economy as a "hegemonic order" and how it deploys the "control utility of network technology" to produce that order or the "universal homogeneous state" would think that "new information and communication technology has not been to free and empower ordinary people but to tighten the screws and make their global economic and political rulers richer and less visible than ever before." Likewise, "insofar as they bolster the already formidable control of capital over the means of power, computer networks are an essentially conservative, not revolutionary, technologyconservative, that is, of the prevailing liberal and capitalist order." See Darin Barney, Prometheus Wired: The Hope for Democracy in the Age of Network Technology, Chicago: University of Chicago Press, 2000, p. 188.
}

\section{Two Edge Roles of Technology}

We can understand the premise of technology's role over society in two opposite ways: As a self-correcting system by Mesthene and as a form of life by McDermott. While the former implies that technology has advantages as well as disadvantages and this does not have to do with our freedom of decision-making since it is almost neutral system, the latter asserts that it is not an arbitrary choice, but an imposition concerning the way we should live with and thereby a tool of suppression of humanity. Since two views are based on and augment certain definitions and characteristics of decision-makers of technology, these two edges about technology's role over society provide us a heuristic tool.

According to Mesthene, technology is "the organization of knowledge for practical purposes." This "organized knowledge" motors social change in creating simultaneously positive and negative effects. In order to understand the impact of technology, we should not isolate either of them and take both at the same time. In fact, what we see as problems or negative effects of technology could be messengers of potential technological advances. Even institutional structures and cultural attitudes of society are subject to that notion: They could offer new opportunities. Yet, since our society depends on individuals and firms, which are looking out new opportunities and they benefit to do so, we cannot realize external benefits embedded in new technologies. These externalities could be either negative or positive. Though positive opportunities are eagerly looked out, there is no way to know what negative externalities are, because "it has not been anybody's explicit business to foresee and anticipate them". 5 Technological advances create new opportunities and thereby the alteration of social structures. Negative externalities are because of older structures since they are inadequate to serve new purposes. Individual purposes, thus, without concentrating to what costs we will have at the end, constitute "the institutional fabric" of the society. The negative externalities, that we face is a sort of cost of our individual freedom to pursue our goals whatever their consequences are. In this regard, technology is like a religion: Positive or negative outcomes are not inherent in the technology, yet they depend on "what man will do with technology." Actually, we cannot attempt to measure or control negative externalities, because these attempts often appear to threaten our freedoms of decision making. If we continue to have positive effects of technology, we should learn to live with negative externalities which would be solved by technology soon. In the long run, that is for sure, technology would maintain general welfare. In this

\footnotetext{
${ }^{5}$ Emmanuel G. Mesthene, "The Role of Technology in Society", in Teich, Ibid, p. 85.

${ }^{6}$ Mesthene, Ibid, p. 90.
} 
context, Mesthene maintains that since ours is a knowledge society, incumbents of technocratic roles as problem solvers get decision making power. As long as they use "organized knowledge for practical purposes", they would be able to get decision making power. So there is no need to worry about misuse or fraud of authority, because they would be able to take reliable decisions based upon reliable knowledge.

Whereas, McDermott thinks that this view, he calls laissez-innover, is simply to keep positions of those who are in power. The reason is that, technology is a way of "rationalized control over large groups of men, events, and machines by small groups of technically skilled men."7 The very notion of negative externalities is a "production" for having technology's benefits while avoiding its costs. He thinks that defining technology "the organization of knowledge for practical purposes" is problematic. Attributing to technology "so much flexibility and 'scientific' purity" is taking market as long-term solution for economy. By coining the term laissez-innover, he criticizes the idea that "if the technology or innovation is allowed, will the maximum social good be realized?" ${ }^{8}$ He thinks that concentrating on negative externalities as temporary technical problems creates a ruling technocrats class. Those who got the power as incumbents of technological decision making positions not by their, say, patrimonial characteristics, but by technological skills as problem-solvers are in charge for our own good. They have a bias against ideologies since they are committed to scientifically deal with problems. What it means that we can trust them because of their specific training and professional commitment. To McDermott, this is "an air of mystification around technology's managers." At this point, he rearticulates the functions of technology decision makers. In fact, they are technical and scientific elites who have highly sophisticated training and education since technology requires doing so. They consist of a ruling class to control masses. So, that enforces the separation between ruling technocrats class and lower classes, a separation enhanced by technological advances and laissezinnover ideology. Besides, the point of "problem solvers" is to assert that technological systems in fact could operate without intervention of human factor. They are resistant to such intervention and do make sure that it is minimal which otherwise would not be "classified" and eventually trusted. In this regard, McDermott argues that technology creates its own politics. Therefore, he lessens the importance of decision makers of technology by calling "technical experts", who make the system rational and efficient, by filtering out the "nonrational" or "nonefficient" elements. ${ }^{10}$

\footnotetext{
${ }^{7}$ McDermott, Ibid, p. 110.

${ }^{8}$ McDermott, Ibid, p. 115.

${ }^{9}$ McDermott, Ibid.

${ }^{10}$ McDermott, Ibid, p. 110.
}

In fact, both views implicitly propose a role definition of decision maker of technology. When this role is defined as "problem solver", we should be persuaded that this role model does not misuse technology, because otherwise that would not be elevated to such a position. The incumbents of this model are isolated from ideological or political thinking in reshaping technology since they use organized knowledge in a centralized (which means controllable) and institutionalized way. At first glance, it seems that this model has power in terms of determining and reshaping technology because they are elevated and granted to do so. Yet, the very definition of "problem solvers" implies a secondary and complementary function, not a preliminary and determinant factor. Further, the premise of practical purposes is vague. It appears that technology, as a self-correcting system, settle on the practical purposes, not the work force of technology.

On the other hand, when we take our role models as technical experts, we are persuaded that this role model is used to control masses. By acquiring skills and sophisticated education, they are elevated into ruling class whose interests determine technology. Again, this model, yet negatively looking, appears to adore decision makers of technology in terms of determining technology. However, it still praises the organized system and disregards the personal freedom of choice. Thus, it does not make room for individual decision making, reducing the politics of technology into a traditional class conflict base.

Either as "problem solvers" or "technical experts", the characteristics of incumbents of technological positions seem very problematic in terms of their roles in shaping technology. Are they so disinterested and unbiased on creation of technology? Can we reduce their roles as such? How can we make sure that they are neutral? If we put their roles that way, what about freedom of individual decision making? Next section tries to determine specific guidelines in order to deal with these questions.

\section{Useful Guidelines for "Job Specifications" of Technology Decision- Makers}

Inspiring two contradictory views outlined above, now, we try to propose two specific guidelines for investigating specifications of technology decision makers, attitudes and positions as well as for having some reference points with which we can evaluate the decision makers of the Internet.

The first guideline refers to "problem solver" as distinctive characteristic of decision makers. This characteristic requires that decision makers place within brackets their personal beliefs and values about the use of technology, including the "bias" that technology has its own politics. Since they 
achieve to get their positions through a selective process, they have already been able to think ideologically-unbiased. That is why they are called "problem solvers". Once we take them as problem solvers, then, we accept the notion that there is no misuse of technology. Yet, it does not still abandon our need to define the very purpose of use of technology. Indeed, it needs a certain definition, because it is unclear to determine "practical purposes" on which decision makers build technology. How do we know they are unbiased or "ideology-free"? Being aware of these challenges, Mesthene proposes a new term "institutional innovation". To deal with the new problems because of new technologies and perhaps to make "practical purposes" understandable, he offers to enlarge public decision making. This enlargement has two consequences. First, we should have reliable knowledge and base our decisions on a particular model of society since all decisions are interrelated and thereby affect the whole society. Second consequence is the need of what he calls "institutional innovation". This is to restructure decision making process. Is it a new way to be able to determine the effects of society so that enlarging the positive effects of society? Though it is not clear, the term "institutional innovation" seems not to support that decision makers of technology are only problem solvers. Rather, it undermines individual decision making, by alternating a motor of technological advancements with a static, determined and proposed mechanism that allows allegedly public to join decision making process. This raises an apparent paradox already embedded in the conception of "problem solvers". If we establish a mechanism socalled "institutional innovation", would not it be at the expense of individual decision making? More importantly, taking them as such is reducing their role into a static and non-innovative way, by assuming them reactive not proactive. Thus, it should be clear that such use of the term "problem solvers" implicitly undermines the freedom of individual decision making and minimize the role of decision makers of predetermined set of assessments.

Second guideline refers to "technical experts" as distinctive characteristic of decision makers. This characteristic requires that decision makers are highly specialized workforce employed to make sure that the system works well, which is the domination of a ruling class over masses. Technology and its workforce, in this regard, are not but the agencies of highly centralized and intensive social control. Technology has not only its own politics, but also creates its own working and managing classes. Recalling to return class-based politics, this interpretation of politics of technology seems to ignore the potential contributions of so-called technical experts inherent in their decision making process. Indeed, it is not absolute to argue that the only motivation for technocrat class is to keep their positions intact. Seeing technology as a tool used to control lower classes is, to some extent, ignoring the innovative and entrepreneurship characters of workforce of technology. As a matter of fact, the incentive and motivation for advancement of technology cannot be simply reduced into class conflicts or power relations. This model, to some degree, can work fine, for instance, for explaining the relationship between complex structures of technology and highly skilled and educated workforce in terms of social organization of modern technology, but some of the early motivations that create new technologies, in particular freedom of individual decision making and innovation, make clear that technocrat class do not necessarily exist to control lower classes and thereby their purpose of technological advancements to keep the status quo. Actually, the term technical expert and understanding what underlies this term is far away to explain what motivates the pioneers of technology. Is it reasonable to diminish of keeping class domination, a vaguely proposed claim? At this point, the term selffulfillment that McDermott uses, being only reward of technocrat ruling class is also insufficient in explaining the motivations behind the early history of new technologies.

It appears that, consequently, two contradictory views of politics of technology offer heuristic tools with which we can have some points about the relation between individual decision making and virtues of technology, even though they lack absolute explanations. Simply summarizing, first view is an optimistic one, appraising technocrat class for their knowledge and skills, yet reducing their roles into static and standardized patterns. Although we cherish the positions of decision makers of technology, we, actually, miss their individual freedom on decision making process. On the other hand, second view is a pessimistic one, blaming that class about using technology for their interests, yet ignoring totally thereby missing real motivations embedded in the formation of new technologies. Again, we cherish their positions yet we do not only dislike their misuse of power but also oppose the notion that they are only motivated to control masses and keep status quo. By having these in mind, now, let us look at how the politics of newest form of technology, the Internet, is shaped?

\section{The Politics of A New Technology: Internet}

The politics of the Internet in terms of guidelines that we offer above requires a historical overview of this revolutionary information infrastructure. But before this, as a technological form, what characteristics of the Internet and its inventors allow us to criticize two views of technology of politics? What uniqueness of the Internet and its inventors make possible for us a "reverse reading of technology" by arguing that the Internet and particularly its first pioneers do not fit the continuum 
ranging from Mesthene to McDermott? Answers to these questions proceed in the following set of arguments:

1. The Internet as a technological form has unique characteristics that challenge the notions of technology, which are used by either Mesthene or McDermott.

2. That the very nature of the Internet is partly, if not mostly, shaped by the characteristics of inventors of the Internet as free-thinkers is apparent.

The first argument is based on the fact that unlike other all mediums before, the Internet allows anyone to communicate instantly with others worldwide. As a network of networks operating "on the basis of multiple implementations of accepted, non-proprietary protocols, standards and interfaces", ${ }^{11}$ it transcends national borders and eliminates barriers to the free flow of information. Likewise, there is no central unit in the structure. ${ }^{12}$ Another difference from other forms of communication is its multi-multi character; actually the Internet allows responsive communication from one-to-one, from one-to-many, and from many-to-one. It permits everyone easily to join itself. ${ }^{13}$ Rather, "the digitization of information and the ability to transmit it over the telephone network, combined with the decentralized nature of the Internet, mean that the Internet has essentially unlimited capacity to hold information." ${ }^{14}$ It allows not only users to choose their contents, but also develop their standards and adapt them without changing and affecting the nature of the infrastructure. Thus, current nature of the Internet, open and decentralized, exhibits a unique character amid other forms of communications ever created.

This uniqueness of the Internet has shattered not only the domination of traditional forms of communication in terms of freedom of voices, but also the intentions of control over media. According to Newhagen, "the very architecture of the net will work

\footnotetext{
${ }^{11}$ Regardless of Frontiers, Protecting Human Right to Freedom of Expression on the Global Internet, Global Internet Liberty Campaign, http://www.cdt.org/gilc/regardlessoffrontiers.html. ${ }^{12}$ Having no control unit would be made possible by dividing messages into separate packets each of which had been individually authorized. That was because of the assumption that network would always be seen as unreliable. Yet, to some, it has become its main strength. See Robert Kahn, "Evolution of the Internet", Chapter 11, Revolution in US Information Structure, National Academy Press, www.nap.edu.

${ }^{13}$ It is so important that, according to Kapor, "future generations will be indebted to this community for the wisdom of building these types of open systems." See Mitchell Kapor, Big Dummy's Guide to the Internet, http://www.umich.edu/ archive/linguistics/bigdummy sguidetotheinternet.

${ }^{14}$ Regardless of Frontiers, Ibid.
}

against the type of content control these folks (the masters of mass media) have over mass media" 15 In fact, "they have yet to grasp that the Internet can never be merely another profit center in their dreams of empire", because "the Net is built to smash monopolies." 16 Even there are some attempts to monopolize the Internet, there will be always "unpaved" portions of cyberspace, "thereby opening the door to a genuine cultural and political renaissance." 17 This is so obvious that discussing the freedom of Internet is not an issue: "That seems guaranteed." 18

What is the origins of uniqueness of the Internet? What makes possible to have an open, and decentralized information structure? According to Kahn, there are initially two reasons: "Far-sighted investment by the United States government and the active involvement of the research community." 19 Regarding the government's role in forming and reshaping the structure of the Internet, the supports of United States Government, Defense Advanced Research Project Agency (DARPA) initially, and later the National Science Foundation (NSF), the Department of Education (DOE) and other agencies and departments are obvious. Especially the projects and research focused on new information infrastructure that became a base for the Internet in 1960s and 1970s were not enough attractable for private computer companies. ${ }^{20}$ Government's not only dedications to highly advanced projects but also successful handling of this issue in terms of management and operation have paved the way of the Internet.

Further, some decisions by the FCC have critical impacts on the development of the Internet. For example 1968 Carterfone decision, determining that customers of the AT\&T could connect their own equipment to the telephone network so long as the equipment did not in fact harm the functioning of the

\footnotetext{
${ }^{15}$ John Newhagen and Sheizaf Rafaeli, "Why Should Communication Researchers Study the Internet: A Dialogue", Journal of Communication, Vol. 46, No.1. ${ }^{16}$ Steven Levy, How the Propeller Heads Stole the Electronic Future, NYT Magazine, Sept 24, 1995.

${ }^{17}$ Quoting from Flowers, 1995: Robert W.

McChesney, The Internet and U. S. Communication Policy-Making in Historical and Critical Perspective, http://www.robertmcchesney.com/Articles.htm.

${ }^{18}$ Robert W. McChesney, The Internet and U. S. Communication Policy-Making in Historical and Critical Perspective,

http://www.robertmcchesney.com/Articles.htm ${ }^{19}$ Kahn, Ibid, p. 158.

${ }^{20}$ In fact, in the early 1970 s, the government wanted to sell off the ARPANET to the private sector. Private sector declined it, reasoning that that technology was incompatible with their network. See Cass Sunstein, republic.com, Princeton University Press, 2001, p. 132.
} 
network, opened the door to the improvement of the modem.

The second reason of the unique nature of the Internet comes from pioneers of new information infrastructure. Their commitment to open, decentralized and free cyberspace, as we argue, has not only made their positions exclusive in terms of freedom of decision making, but also had their products, the Internet, an unprecedented effect, breaking the ground where technology challenges human life, threatening its freedom.

\section{Pioneers Inspired to Change the World}

According to Rheingold, "the most important parts of the Net began as dreams in the imaginations of a few specific people, who acted on inspiration rather than orders." Neither national defense concerns nor profit motive, but diligent scholars, enthusiastic researchers, and keen teenagers have created the Internet, willing to change the world. $^{21}$

If there is a need to classify those who pioneered, the very first pioneer of the Internet's pioneers may be Vannevar Bush. Considering a future device called memex, he was first to describe the very nature of the information infrastructure. Memex, according to Bush, is "a device in which an individual stores all his books, records, and communications, and which is mechanized so that it may be consulted with exceeding speed and flexibility." It consists of a desk, which can be operated from a distance, screen, keyboard, and sets of buttons and levers. Its contents would be recorded on microfilms. ${ }^{22}$ By having this visionary mind, he did not only inspire many, but also had a key role in establishing a team of pioneers (later developed the ARPANET), which initiated many projects that changed information infrastructure, "bringing the government, military and elite academic researchers into a closer embrace than ever before." 23

Publishing a number of papers related with human and computer interaction in the early 1960 s, J. C. R. Licklider is another pioneer. His "Galactic Network" concept proposing a globally interconnected set of nodes through which everyone could quickly access data and programs from any site was very alike of the Internet. He was the first head of the computer research program at DARPA. Though his funding was very limited and computer industry was not ready to

21 Howard Rheingold, The Virtual Community, Chapter 3, http://www.rheingold.com/vc/book/3.html

${ }^{22}$ Vannevar Bush, "As We May Think", Atlantic Monthly, 1945, http:// www.csi.uottawa.ca / dduchier/misc /vbush /awmt.html

${ }^{23}$ G. Pascal Zachary, Endless Frontier: Vannevar Bush, Engineer Of The American Century, The Free Press, 1997. the idea of time sharing in machine resources, his vision and persistence made the projects going. He chose most of the first pioneers of information infrastructure project. ${ }^{24}$ While directing DARPA, he also helped to the formation of Computer Science Departments at many universities. ${ }^{25}$

In his 1968 paper, "The Computer as a Communication Device," written with Robert Taylor, Licklider defined four principles for human and computer interaction:

1. Communication is defined as an interactive creative process.

2. Response times need to be short to make the "conversation" free and easy.

3. Larger networks form out of smaller regional networks.

4. Communities form out of affinity and common interests. ${ }^{26}$

Defined as "Prophet of the Net" by one scholar, Licklider's vision is seen in the same paper clearly:

"The collection of people, hardware, and software - the multi-access computer together with its local community of users - will become a node in a geographically distributed computer network. Let us assume for a moment that such a network has been formed.... Through the network of message processors, therefore, all the large computers can communicate with one another. And through them, all the members of the super-community can communicate - with other people, with programs, with data, or with selected combinations of those resources." 27

The creators of networking protocol of TCP/IP, Bob Kahn and Vinton Cerf are living examples of the Internet pioneers. They both worked at DARPA on networking projects. At the beginning, Kahn was working alone. In 1972, he gave a demonstration of a network called ARPANET, connecting 40 different computers at the International

\footnotetext{
${ }^{24}$ Robert W. Taylor, In Memoriam: J. C. R. Licklider 1915-1990, Digital Systems Research Center, CA. August 1990.

${ }^{25}$ J.C.R. Licklider, http://www.columbia.edu/ jrh29/years.html ${ }^{26}$ Michael Hauben and Ronda Hauben, "Netizens: On the History and Impact of Usenet and the Internet", First Monday, http://www.firstmonday.dk/issues/issue3_7/index.htm 27 J. C. R. Licklider and Robert W. Taylor, "The Computer as a Communication Device ' reprinted in In Memoriam: J. C. R. Licklider 1915-1990, Digital Systems Research Center, CA, August 1990; originally published in Science and Technology, April 1968. http://memex.org/licklider.html
} 
Computer Communication Conference. That was the first time when the net project gained widely interest. In 1973, Vinton Cerf joined Kahn on this project. They worked on data communications across packet radio networks. They then studied on the development of a standard open-architecture network model, where any computer could communicate with any other. Following statement of Cerf reflects his thoughts about the project:

"I had certain technical ambitions when this project started, but they were all oriented toward highly flexible, dynamic communication for military application, insensitive to differences in technology below the level of the routers. I have been extremely pleased with the robustness of the system and its ability to adapt to new communications technology. One of the main goals of the project was "IP on everything." Whether it is frame relay, ATM, or ISDN, it should always be possible to bring an Internet Protocol up on top of it. We've always been able to get IP to run, so the Internet has satisfied my design criteria. But I didn't have a clue that we would end up with anything like the scale of what we have now, let alone the scale that it's likely to reach by the end of the decade. It seems likely that the Internet will continue to be the environment of choice for the deployment of new protocols and for the linking of diverse systems in the academic, government, and business sectors for the remainder of this decade and well into the next." 28

In 1980, TCP/IP, a co-production of Kahn and Cerf, was decided that it would be used in the preferred military protocols. Yet, that was not turning point. The turning point was a perfect example of freedom of individual decision making. In Cerf's own words, it is: "In 1988 I made a conscious decision to pursue connection of the Internet to commercial electronic mail carriers. It wasn't clear that this would be acceptable from the standpoint of federal policy, but I thought that it was important to begin exploring the question." ${ }^{29}$

Kahn's early goals on this project are remarkable in terms of a perspective of a decision maker of technology, as well. Four basic rules, namely network connectivity, distribution, error recovery and black box design, affected Kahn's thinking:

1. Each distinct network would have to stand on its own and no internal changes could be required to any such network to connect it to the Internet.

2. Communications would be on a best effort basis. If a packet didn't make it to the final destination, it would shortly be retransmitted from the source. Black boxes would be used to connect the

${ }^{28}$ Vinton Cerf, "How the Internet Came to Be" The Online User's Encyclopedia, by Bernard Aboba, Addison-Wesley, November 1993.

${ }^{29}$ Cerf, Ibid. networks; these would later be called gateways and routers.

3. There would be no information retained by the gateways about the individual flows of packets passing through them, thereby keeping them simple and avoiding complicated adaptation and recovery from various failure modes. operations level." ${ }^{30}$

4. There would be no global control at the

Similarly, same sort of vision is reflected in the thinking of Tim Bernard Lee who invented WWW in March 1989. His project initially had two main goals: First, like Kahn's design for TCP/IP, WWW hypertext system should have an open architecture, and second, it should be distributed over a communications network.

In his "The World Wide Web: A Very Short Personal History" Lee summarizes his efforts to standardize an "Universal Document Identifier", mentioning how his boss supported his experiments. ${ }^{31}$ WWW was the realization of Lee's dream of creating a "common information space in which we communicate by sharing information". The remaining part of the dream was yet to come. It was web's realistic mirror function that "once the state of our interactions was on line, we could then use computers to help us analyze it, make sense of what we are doing, where we individually fit in, and how we can better work together." Will it happen so? "(It) has yet to happen, but there are signs and plans which make us confident. The great need for information about information, to help us categorize, sort, pay for, own information is driving the design of languages for the web designed for processing by machines, rather than people. The web of human-readable document is being merged with a web of machine-understandable data. The potential of the mixture of humans and machines working together and communicating through the web could be immense",32

Tracking the dreams and decision making processes of first pioneers, Douglas Engelbart, developer of the graphical user interface, first working hypertext system and first mouse, is also a key figure. Interestingly, his first motivation came from Vannevar Bush's article about his vision for the "memex". Subsequent years, he published a paper called, "Augmenting Human Intellect: A Conceptual Framework", visioning his own information

\footnotetext{
${ }^{30}$ A Brief History of the Internet Barry M. Leiner, Vinton G. Cerf, David D. Clark, Robert E. Kahn, Leonard Kleinrock, Daniel C. Lynch Jon Postel, Larry G. Roberts, Stephen Wolff, http://www.isoc.org/internet-history/brief.html

${ }^{31}$ Tim Bernards Lee, The World Wide Web: A Very Short Personal History, http://www.w3.org/People/BernersLee/ShortHistory.html

${ }^{32}$ Tim Bernards Lee, Ibid.
} 
infrastructure. Next excerpt is notable vision of this inventor:

"My professional motivations are strongly oriented toward maximizing the benefit which society might derive from the advancements in the computer field. I might say then that my professional interests are toward the application of automatic informationhandling equipment for helping human society, in the most significant way possible."33

A bit different perspective can be seen on Ray Tomlinson, first sender of e-mail. When asked what inspired his invention, he said that "There was no directive to 'go forth and invent e-mail."' And added: "Mostly because it seemed like a neat idea". Setting out to adapt CYPNET to use SNDMSG to deliver messages to mailboxes on remote machines, through the ARPANET, he feels in a humble way, citing that was "just a minor addition to the protocol." 34

Regarding the outstanding contributions of first pioneers of the Internet to the uniqueness of it, it should be emphasized that these key figures have not only played important role in development of the infrastructure, but also they have been -and still arevery and closely interested in policy and technological changes that could affect the very nature of it. They do so by either participating in government organs or forming their own organizations. The example of former is National Research Council's Computer Science and Telecommunications Board (CSTB) committee chaired by Leonard Kleinrock, one of the pioneers of digital network communications, and helped build the early ARPANET. Being active in policy making with the government, Kleinrock has affected the formation of current framework with his influential 1994 report Realizing the Information Future; The Internet and Beyond. Pursuing the idea that "the nature of the services and styles it (the Internet) can produce is limited only by the imagination of its practitioners", Kleinrock is a typical example of the Internet's first pioneers who choose to keep the dream alive. ${ }^{35}$

In this regard, it could be said that some organizations and research projects funded by governments (the ARPANET in the United States, the network of the National Physical Laboratory in the United Kingdom, CYCLADES in France, and other

${ }^{33}$ D. C. Engelbart; MEMORANDUM-Possibilities for Teaching Machine Activity at SRI; May 18, 1960, http://www.histech.rwth-

aachen.de/www/quellen/engelbart/B15_F4_TeachMac h.html.

${ }^{34}$ Todd Campbell, The First E-Mail Message, Pretext Magazine, March 1998.

35 University of California (UCLA), Leonard Kleinrock's Personal History/Biography, The Birth of the Internet, http://www.lk.cs.ucla.edu. networks around the world) have prominent roles in fostering the development of new information infrastructure. Yet, even in these organizations, we see same pattern of thinking rooted in decision making process of individual pioneers. Though McDermott thinks in a different way, hypothesizing that advanced technological institutions are agencies of highly centralized and intensive social control ${ }^{36}$, on the contrary, workforce of these organizations established primarily for military purposes ${ }^{37}$ could mostly achieve to determine the early goals and structure of the new information infrastructure in a more independent and free way. Funded by government, these organizations were directed to highly complex research projects. Yet direct control and coercion that would manipulate the researchers were not existent. Thus, they became platforms of freedom of decision making. One of the reasons of this phenomenon may be the management and operation of these organizations. Managed by visionary scientists, for example like J.C.R. Licklider, these organizations were able to employ "unorthodox computer programmers and electronic engineers who wanted to redesign the way computers were operated. ${ }^{38}$ It would be useful to look closely to a few of these organizations.

Surely, the most remarkable case is ARPA. ARPA (later became DARPA) was the U.S. Department of Defense's Advanced Research Projects Agency (ARPA). J. C. R. Lick became head of ARPA in 1962 for creating and managing a program for funding research. In 1966, Larry Roberts proposed the ARPANET to ARPA. While the very aim of the organization was militaristic since it was funded by military, Robert's proposal had a more technically focused purpose. It was to explore computer resource sharing and packet switched communications and had nothing to do with nuclear war or survivability." 39 Regarding the rumor that the Internet was created by military to have survivability of information in a nuclear war depends upon a paper by Paul Baran. Yet, ARPANET started earlier than this paper, based on the

\footnotetext{
${ }^{36}$ McDermott, Ibid, p. 121.

37 "Bear in mind that the existing infrastructure was created for something else. It was created for reasons that you wish it hadn't been [military]. But without that impetus, the World Wide Web would never have happened. The fax machine would never have come about if it weren't for existing phone lines. Phone lines were a technology that created opportunity." (Interview with Vincent Cerf) For full text of interview see Erica Rex, "The Internet: Past, Present and Future, JavaWorld, April 1997, http://sunsite.compapp.dcu.ie/IJUG/javaone/index.htm $l$.

38 Lawrence G. Roberts, March 22 1997, http://www.ziplink.net/ lroberts/InternetChronology.h tml

${ }^{39}$ Roberts, Ibid.
} 
work Licklider, Kleinrock and Roberts. ${ }^{40}$ Nonetheless, it is difficult to argue that the government funding and military motivations have secondary importance. ${ }^{41}$

ARPA has basically pioneered and sponsored three key projects: Advanced Research Project Agency Network (ARPANET), packet radio network, and packet satellite network. According to Kahn, "each of these three networks was individually designed and implemented, but most importantly, the Internet architecture was created to be independent of the detailed design or implementation of any of its constituent networks." He thinks that the success of the Internet lies "on the underlying computer communications technology that had been pioneered in the ARPANET." Further, to him, two important characteristics of the Internet as being no single entity responsible for the overall performance of network and layered host protocols are also aimed in the ARPANET project. $^{42}$

Another key organization, though its contribution is accordingly limited, is a non-US research center called CERN- the European Laboratory for Particle Physics. When it was founded in 1954, CERN was based upon the idea that atmosphere of freedom - freedom to doubt, freedom to enquire and freedom to discover- is essential for scientific research. Throughout years, CERN has been "the world's largest research laboratory with over 50\% of all the active particle physicists in the world taking part in over 120 different research projects. 3000 staff members, 420 young students and fellows supported by the Organization and 5000 visiting physicists, engineers, computer experts and scientists specializing in a variety of front-line technologies are collaborating with CERN from 40 countries and 371 scientific institutions. ${ }^{, 43}$ Not surprisingly, the researchers of this center have made significant contributions. The WWW project was originally developed by

\footnotetext{
${ }^{40}$ Roberts, Ibid.

41 "ARPA wouldn't have happened if what used to be the Soviet Union hadn't shaken a complacent U.S. awake with a tin can in the sky, Sputnik. Wars do wonders for the advancement of technology, and the Cold one was certainly no exception. The way to get a technology advanced is to gather a lot of really smart people under one roof and get them to concentrate on a single project. Of course, that takes some organization and money. Where does that come from? But that's another can of worms - to be opened with relish at a later date. In this case, it was the only body that had a stake in making sure the Net worked - the government." (David Hudson, "Con.txt", Rewired: JOURNAL OF A STRAINED NET, August 9th, 1996.)

${ }^{42}$ Kahn, Ibid, p. 159.

${ }^{43}$ Net Valley, http://www.netvalley.com/archives/mirrors/CERNPR11_94E40thAnni.htm
}

researchers of CERN in $1990 .{ }^{44} \mathrm{CERN}$ has also played an important role in development of the Internet protocols. First internet protocol was used there during the second phase of the STELLA Satellite Communication Project, from 1981-83, a project inspired by the ARPA IP model. ${ }^{45}$

Apart their supportive and directive roles through consultation to public and private sectors, the first pioneers of the Internet have also formed critically functioning organizations in establishing standards and forming other components of the Internet. Among the examples of that kind of organizations are Internet Society, IETF, the World Wide Web Consortium (W3C), the Internet Corporation for Assigned Names and Numbers (ICANN), including Commercial Internet Exchange (CIX), aiming to facilitate the exchange of traffic among commercial internet service providers. ${ }^{46}$ They symbolize the ongoing efforts of the first pioneers of the Internet. Working together, these organizations make sure that the unique nature of the Internet cannot be sacrificed. For example, the W3 Consortium formed by Tim Bernard Lee, the inventor of WWW, as an independent standards making body was to ensure universality of functionality across the industry. Convincing Michael Dertouzos, the head of MIT's Laboratory for Computer Science, Lee established W3C in 1994, in order to "oversee development of common web protocols and promote web interoperability." ${ }^{47}$ The formation and operation of the $\mathrm{W} 3 \mathrm{C}$ is a manifestation of the Internet as most open, decentralized and free medium of all times: Before promoting their standards, W3 staff present a sample code, allowing everybody to raise any concern. Then, they release the standards for the implementation to promote each of their standards.

\section{Conclusion}

One scholar points out the historical significance of the Internet: "Instead of a small number of groups having privileged positions as speakers-broadcast networks and powerful newspapers-we are entering an era of communication of the many to the many. . the nature of the technology itself has opened up a space of much greater democratic possibility." ${ }^{48}$ In this paper, we argue that this is because of the creative roles of first pioneers in the formation of the very structure of the Internet. Emphasizing their freedom of decision making in establishing the new information infrastructure, we build my argument in to context of two contradictory views of technology of politics.

\footnotetext{
${ }^{44}$ CERN,

http://map.web.cern.ch/lhc/general/gen_info.htm

${ }^{45}$ Net Valley, http://www.netvalley.com/intval2.html

${ }^{46}$ Kahn, Ibid, p. 158-159.

47 The W3 Consortium,

http://livinginternet.com/w/wi_w3c.htm

${ }^{48}$ McChesney, Ibid.
} 
Either as "problem solvers" or "technical experts", we try to show that the defining characteristics of technology decision makers do not fit in to the frame of first pioneers of the Internet. We never accept the idea that as technical experts or problem solvers, thereby being participators of decision making process, are not interested in shaping the technology. As a matter of fact, they cannot be neutral. In the example of the internet, we believe first inventors of the Internet had their roles very positively. They always had same spirit, making the Internet not only a positive technological contribution to humanity, but also a platform of choice, a mark of respect in terms of freedom of decision making, a spirit which is still alive today.

It should be emphasized that, however, we are not still in a position where we can measure the outcome truly. This is because of the fact that the revolution or evolution whatever it is, is continuing. In a medium which moves speed of light, everything can change at the same speed. Thanks to their ongoing efforts, most of the first pioneers are in charge and still trying to keep "dream" alive. This is a dream that can change the relation between human and technology in a positive way.

\section{REFERENCES}

Albert H. Teich (Editor), Technology and Future, St. Martin's Press, Fifth Edition, NY, 1990.

Center for Democray and Technology, https://www.cdt.org/gilc/regardlessoffrontiers.html

CERN,

http://map.web.cern.ch/lhc/general/gen_info.htm

Darin Barney, Prometheus Wired: The Hope for Democracy in the Age of Network Technology, Chicago: University of Chicago Press, 2000.

David Hudson, "Con.txt", Rewired: JOURNAL OF A STRAINED NET, August 9th, 1996.

D. C. Engelbart; MEMORANDUMPossibilities for Teaching Machine Activity at SRI; May 18, 1960, http://www.histech.rwthaachen.de/www/quellen/engelbart/B15_F4_TeachMac h.html.

Dublin City University, http://sunsite.compapp.dcu.ie/IJUG/javaone/index.htm

Emmanuel G. Mesthene, "The Role of Technology in Society”, in Teich, Ibid, pp. 85, 90.
Erica Rex, "The Internet: Past, Present and Future, JavaWorld, April 1997, http://sunsite.compapp.dcu.ie/IJUG/javaone/index.htm 1.

G. Pascal Zachary, Endless Frontier: Vannevar Bush, Engineer Of The American Century, The Free Press, 1997.

Community, Chapter 3, http://www.rheingold.com/vc/book/3.html

Internet Society, http://www.isoc.org/internethistory/brief.html

J.C.R.

Licklider, http://www.columbia.edu/ jrh29/years.html

J. C. R. Licklider and Robert W. Taylor, "The Computer as a Communication Device ' reprinted in In Memoriam: J. C. R. Licklider 19151990, Digital Systems Research Center, CA, August 1990; originally published in Science and Technology, April 1968. http://memex.org/licklider.html

John McDermott, "Technology: The Opiate of the Intellectuals", in Albert H. Teich (Editor), Technology and Future, St. Martin's Press, Fifth Edition, NY, 1990, pp. 110, 115.

John Newhagen and Sheizaf Rafaeli, "Why Should Communication Researchers Study the Internet: A Dialogue", Journal of Communication, Vol. 46, No.1.

Langdon Winner, The Whale and the Reactor A Search for Limits in an Age of High Technology, The University of Chicago Press, 1986.

Lawrence G. Roberts, March 22 1997, http://www.ziplink.net/ lroberts/InternetChronology.h tml

Michael Hauben and Ronda Hauben, "Netizens: On the History and Impact of Usenet and the Internet", First Monday, http://www.firstmonday.dk/issues/issue3_7/index.htm

Net Valley, http://www.netvalley.com/ archives/mirrors/CERN-PR11_94E40thAnni.htm intval.htm

Net Valley, http://www.netvalley.com/ intval2.html

Net Valley, http://www.netvalley.com/

Regardless of Frontiers, Protecting Human Right to Freedom of Expression on the Global Internet, Global Internet Liberty Campaign, http://www.cdt.org/gilc/regardlessoffrontiers.html. 
Robert Kahn, Revolution in US Information Structure, National Academy Press.

Cass Sunstein, republic.com, Princeton University Press, 2001, p. 158.

Robert W. McChesney, Quoting from Flowers, The Internet and U. S. Communication Policy-Making in Historical and Critical Perspective, 1995, http://www.robertmcchesney.com/Articles.htm

Robert W. Taylor, In Memoriam: J. C. R. Licklider 1915-1990, Digital Systems Research Center, CA. August 1990.

Steven Levy, How the Propeller Heads Stole the Electronic Future, NYT Magazine, Sept 24, 1995.

Todd Campbell, The First E-Mail Message, Pretext Magazine, March 1998.

The National Academies Press, http://www.nap.edu

The W3 Consortium, http://livinginternet. com/w/wi_w3c.htm
Tim Bernards Lee, The World Wide Web: A Very Short Personal History, http://www.w3.org/People/Berners-

Lee/ShortHistory.html

Todd Campbell, The First E-Mail Message, Pretext Magazine, March 1998.

University of California (UCLA), Leonard Kleinrock's Personal History/Biography, The Birth of the Internet, http://www.lk.cs.ucla.edu

University of Michigan, http://www.umich.edu/ archive/linguistics/bigdummy sguidetotheinternet

University of Ottawa, http://www.csi.uottawa.ca/ dduchier/misc/vbush/awm t.html

Vannevar Bush, “As We May Think", Atlantic Monthly, 1945, http://www.csi.uottawa.ca/ dduchier/misc/vbush/awm t.html

Vinton Cerf, "How the Internet Came to $B e$ " The Online User's Encyclopedia, by Bernard Aboba, Addison-Wesley, November 1993. 